\title{
PISTE: A Snow-Physics Model Incorporating Human Factors for Groomed Ski Slopes*
}

\author{
Rosie HowARD AND ROLAND STULL \\ Department of Earth, Ocean and Atmospheric Sciences, University of British Columbia, \\ Vancouver, British Columbia, Canada
}

(Manuscript received 6 January 2014, in final form 21 July 2014)

\begin{abstract}
Accurately calculating snow-surface temperature and liquid water content for a groomed ski run, known as a ski piste, is crucial to the preparation of fast skis for alpine racing. Ski technicians can use forecasts of these variables to reduce ski-snow friction by applying layers of wax ahead of time. A new one-dimensional numerical Lagrangian snowpack model, Prognostic Implementation for Snow Temperature Estimation (PISTE), is presented that solves the heat-, liquid water-, and ice-budget equations to calculate these snow variables. In addition, the human effects of skiing and grooming are modeled. Meteorological measurements from a 5-day, clear-sky case study at a ski piste on Whistler Mountain, British Columbia, Canada, are prescribed to PISTE as boundary conditions. Because of a lack of interior snowpack measurements, PISTE was spun up from a dry, isothermal snowpack using repeated boundary conditions from 1 day of measurements. Initial conditions for the main model run that used the subsequent 4 days were taken from this spinup. Simulated and measured snow-surface temperatures show very good agreement, with slight cold daytime and warm nighttime biases (averaging $0.5^{\circ}$ and $1^{\circ} \mathrm{C}$, respectively). The modeled behavior of snowpack temperature and liquid water content profiles is consistent with previous literature having similar radiative boundary conditions. The case study indicates that PISTE is useful under simple conditions. It shows the potential to be developed into a more sophisticated model that can incorporate complex boundary conditions such as cloudiness and precipitation and can be driven by numerical weather prediction output.
\end{abstract}

\section{Motivation}

Information on the snow-surface conditions of a ski piste (a groomed downhill ski run) is used by ski race technicians to optimally prepare skis via waxing and surface structuring, with the intention of reducing friction between the snow surface and ski base. Ski-snow friction depends upon many factors such as air temperature and humidity, snow-surface temperature and liquid water content, and snow age and grain size (Howard and Stull 2011), for which different waxes are optimum. Since multiple temperature-specific wax layers are applied as early as the night before a race, this paper

\footnotetext{
* Supplemental information related to this paper is available at the Journals Online website: http://dx.doi.org/10.1175/JHM-D-14-0013.s1.

Corresponding author address: Rosie Howard, Dept. of Earth, Ocean and Atmospheric Sciences, University of British Columbia, 2020-2207 Main Mall, Vancouver, BC V6T 1Z4, Canada. E-mail: rhoward@eos.ubc.ca
}

focuses on forecasting piste snow-surface temperature and liquid water content, to assist in waxing decisions.

Previous snow models have been created primarily for avalanche prediction in natural ungroomed snowpacks, for example, CROCUS (Brun et al. 1989) and SNOWPACK (Bartelt and Lehning 2002). SNOWPACK has also been used (Bethke et al. 2005; Fauve et al. 2008) to optimize timing for ski piste preparation and to predict the snowsurface temperature. These sophisticated models require knowledge of complex stratigraphy and snow grain microstructure, as does the Snow Thermal Model (SNTHERM; Jordan 1991). This information is difficult to obtain on a ski piste before a race without disturbing the course.

Ski piste snowpack density must be high enough (450$650 \mathrm{~kg} \mathrm{~m}^{-3}$; Fauve et al. 2002) to support ski edges during fast tight turns. This high density and hardness make it physically difficult to insert instrumentation, especially without disturbing the state of the snowpack. In addition, skiers frequently traverse the ski run, so scientific instruments mounted on the snow surface are prohibited for safety reasons. Further to this, grooming equipment 
tills the top $10-15 \mathrm{~cm}$ of the snowpack at least once daily, which would destroy subsurface instrumentation.

While the microstructure beneath the snow surface is of direct importance to avalanche forecasting, knowledge of surface variables is more important for the preparation of fast skis. Speculating the initial conditions of interior snowpack microstructure parameters for groomed ski pistes would likely induce errors and make error analysis very difficult. Thus, a one-dimensional model that does not require in situ surface or subsurface snow microstructure observations would find utility for ski pistes.

We present a simplified one-dimensional numerical model, called Prognostic Implementation for Snow Temperature Estimation (PISTE), that estimates vertical profiles of snow temperature, density, liquid water content, and mechanical characteristics of a groomed ski trail. Like previous snowpack models, it solves budget equations for heat, ice, and liquid water, within a snow column. It also includes human activities (skiing and grooming). To our knowledge, no previous snowpack models have attempted to do this.

PISTE is designed to be used just before and during ski racing events. The natural physical processes are modeled specifically for this short time scale (on the order of days)-PISTE is not intended to simulate the seasonal evolution of a snowpack. The model can be applied at any time during the winter, given appropriate initial and boundary conditions.

The Lagrangian model framework, described in section 2, allows model layers to diminish and numerically disappear because of melting, sublimation, and compaction, and for snowfall to add new layers. The PISTE heatbudget equation in section 3 is derived and details of field measurements are provided (see the online supplemental material). The effects of skiers and grooming equipment are described in section 4. To test its utility, PISTE is applied to a 5-day, clear-sky case study, presented in section 5. Results and conclusions are in sections 6 and 7.

\section{Model framework}

As in SNOWPACK (Bartelt and Lehning 2002), we adopt a Lagrangian framework. This avoids the snow advection terms of Eulerian models that can be problematic because of numerical stability and smoothing and allows us to track snowpack layers. On ski pistes, repeated mechanical grooming creates a snow column that does not have "weak" layers nor the sharp discontinuities found in natural snowpacks. Thus, the layers used in PISTE are arbitrary vertical divisions of the smoothly varying snow column. Each layer is approximated as having uniform characteristics, and different layers can have different thicknesses (Fig. 1). The (a)

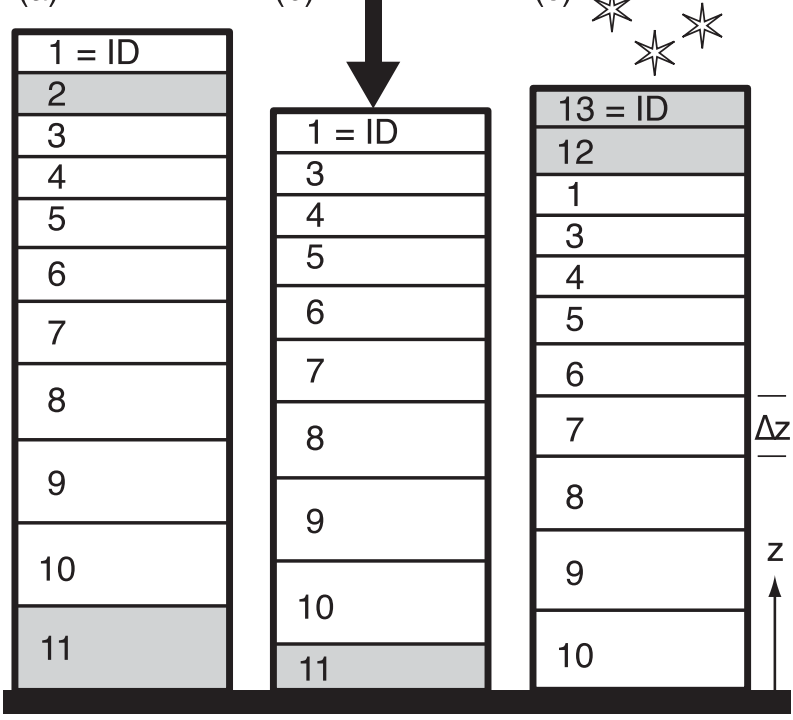

FIG. 1. Example of snow-column characteristics, where each layer is given a unique ID that remains with that layer. (a) Layers can have different thicknesses. (b) Layers can change thickness (e.g., layer 11) or can be merged with a neighboring layer (e.g., layer 2, and later layer 11) because of melting and/or compaction (numerically "disappearing"). (c) New layers can be added, with their unique IDs, such as those caused by new snowfall or by choice of splitting thick layers into multiple thin ones.

thickness $\Delta z$ of any layer can change with time as driven by physics. Thin layers are recommended near the top of the column where vertical gradients are large.

A unique ID is assigned to (and stays with) each layer. For example (Fig. 1), heat from the earth can partially melt and weaken the bottom layer, allowing the weight of the snow column above to compact it. Solar radiation penetrating beneath the snow surface could melt and weaken subsurface layers while IR cooling keeps the layers above frozen, allowing the melt layers to be compacted by skiers. New snowfall could add layers to the column top (not yet tested).

Instead of using arrays to hold layer characteristics, we use a computational structure called a doubly linked list (Fig. 2), where the physical state of each snow layer is stored in a node in that list. Dynamic memory allocation in the Fortran 95 code allows new layers to be added and other layers to disappear (numerically speaking, layers thinner than a user-specified threshold get merged with the layer below). Each layer has a pointer to the layer above and below it, which are redirected as needed to point to new layers or around deleted layers. The linked list is a well-known data structure in computer science (Chapman 2008; Meyer 1988).

The model starts with prescribed initial conditions (layer thicknesses and physical states; see section 5c) and steps forward with time step $\Delta t$ to make the forecast 


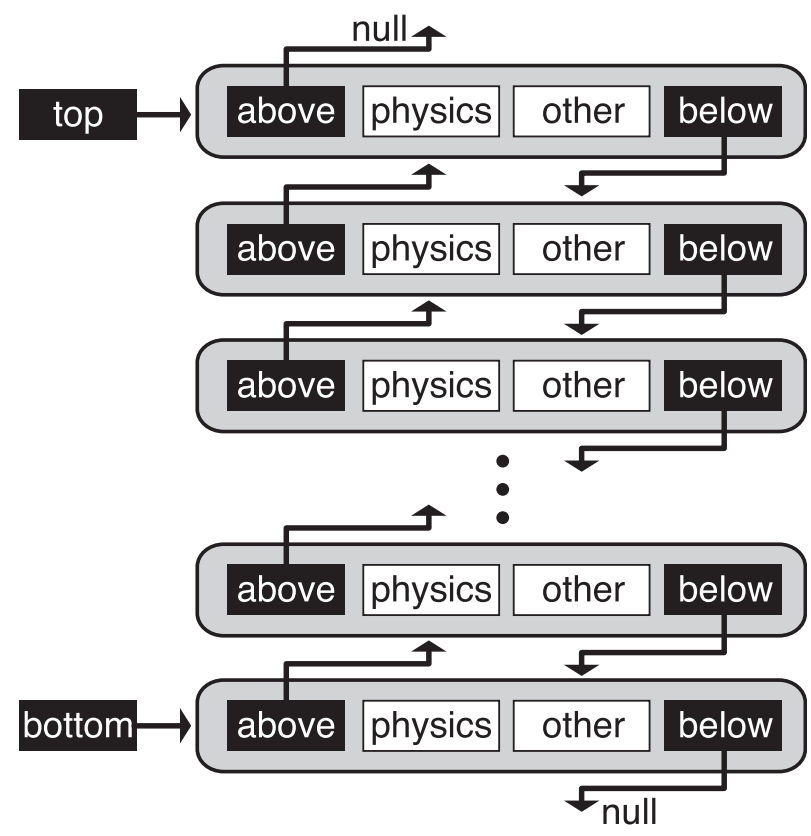

FIG. 2. Structure of the piste model doubly linked list. Each gray box with rounded corners is a compound variable (a node known as a "structure" in C, or a "derived type" in Fortran) that represents a snow layer. Each layer stores the physical state (temperature, density, liquid water content, etc.), other bookkeeping variables such as layer ID and thickness $\Delta z$, and pointers (black arrows) to the layers above and below. Note that any pointer variable (filled black box) points to a whole snow layer (gray box) and not to any specific element within that layer. Additional pointers point to the top and bottom layers. Null indicates no further layers.

or simulation. Time-varying boundary conditions (solar radiation, IR radiation, air temperature, air humidity, wind speed, precipitation, compacting stresses due to skiers or grooming equipment, etc.) are imposed at the top of the snow column as the forecast progresses. At the snow-earth boundary, the ground is assumed to always be at $0^{\circ} \mathrm{C}$ (see section $5 b$ ).

Horizontal fluxes are neglected in this one-dimensional, single-column model. While this is an oversimplification, it is useful for slight to moderate ski slopes, such as our $9.5^{\circ}$ case study slope (section 5). Horizontal stresses, such as gravity-driven snow creep, tend to occur on monthly to seasonal time scales, so these are negligible compared to the effects of grooming equipment over shorter time scales. Future versions of PISTE could allow for the fact that ski slopes can be as steep as $\sim 35^{\circ}$ on some pitches. Vertical fluxes of heat, liquid water, water vapor, solar radiation, the normal stress, and other physical processes are computed for every layer at each time step.

PISTE divides each time step into two stages. The first stage has duration $\Delta t$, during which the budget equations for ice, liquid water, and heat are solved. During this stage, the layer thicknesses $\Delta z$ are assumed constant. If melting or sublimation occurs, sufficient ice matrix remains during that short time step to maintain the layer integrity. The second stage of each time step has zero time duration but models important human processes, addressing a main goal of this paper. During this second stage, snow layers can be compacted, changing $\Delta z$, and the occasional grooming of the top several centimeters of snowpack is modeled (section 4).

\section{Heat-budget equation}

The components of a snowpack and its mass and heat budgets are well documented in the snow-science literature (e.g., Essery et al. 2013) and are used in the avalanche and hydrological models mentioned earlier. The PISTE model heat budget [Eq. (1)] is derived (see the online supplemental material). We use the following notation:

1) Terms that only apply to the top layer are indicated by enclosing them in curly brackets. These are unique physical processes that do not occur or are not modeled in interior layers [e.g., the last term in Eq. (1)].

2) Terms that apply to interior snow layers but have a special form for the top layer are written in pseudomatrix form with square brackets [e.g., the first term on the right side of Eq. (1), where the top element in the brackets applies to the top layer and the bottom element applies to all the other layers].

All fluxes are positive upward. After simplifying the heat budget using ice- and liquid water-budget equations (see the online supplemental material), the resulting temperature $T$ forecast equation for a snow layer in PISTE is

$$
\begin{aligned}
\rho_{s} C_{s} \Delta z \frac{d T}{d t}= & C_{l} \cdot\left[\begin{array}{c}
\rho_{l} \mathrm{RR} \\
M_{\text {in }}
\end{array}\right] \cdot\left(\left[\begin{array}{c}
T_{\text {rain }} \\
T_{\text {in }}
\end{array}\right]-T\right)+\dot{m}_{f}\left[L_{f}+T\left(C_{l}-C_{i}\right)\right]-\Delta V_{i}\left(L_{d}-T C_{i}\right)+\Delta\left(k_{\mathrm{eff}} \frac{d T}{d z}\right) \\
& +\left[\begin{array}{c}
K \downarrow-K \uparrow \\
\left|S_{\text {in }}\right|
\end{array}\right] \cdot\left(1-e^{-\Delta z / \lambda}\right)+\left\{V_{l, \mathrm{sfc}}\left(T C_{l}-L_{v}\right)-F_{H}+F_{\mathrm{IR}, \text { in }}-\varepsilon_{s} \sigma T^{4}\right\},
\end{aligned}
$$

where each term starting from the top left represents, in order, 1) temperature tendency; 2) advection of sensible heat by liquid; 3 ) freezing processes; 4) vapor sublimation/ deposition processes; 5) thermal conduction; 6) solar 
heating; and 7) the surface processes of latent and sensible heat fluxes between the top snow layer and the air and the downwelling and upwelling longwave radiation, respectively. The appendix provides a complete glossary of the variables used (note that some of these variables are used in the online supplemental material). Delta always represents the top minus the bottom of the layer of interest, for example, for water vapor flux, $\Delta V_{i}=$ $V_{i, \text { top }}-V_{i, \text { bottom. }}$

Equation (1) is nonlinear because of the temperature dependence of the coefficients. However, since all temperatures are absolute and vary by a small percentage for a midlatitude site (see section 5), and coldest temperatures are expected at the snow surface, we make the following simplifications. Let $b_{0} \equiv\left[L_{f}+T\left(C_{l}-C_{i}\right)\right] \approx$ $9.0 \times 10^{5} \mathrm{~J} \mathrm{~kg}^{-1}$, with an error of up to $\pm 1 \%$ for temperatures from $0^{\circ}$ to $-10^{\circ} \mathrm{C}$. Let $b_{1} \equiv\left(L_{d}-T C_{i}\right) \approx$ $2.265 \times 10^{6} \mathrm{~J} \mathrm{~kg}^{-1}$, with an error of up to $\pm 0.5 \%$, and let $b_{2} \equiv\left(T C_{l}-L_{v}\right) \approx-1.37 \times 10^{6} \mathrm{~J} \mathrm{~kg}^{-1}$, with an error of up to $\pm 1.5 \%$. With these abbreviations, and after moving the freezing term to the left-hand side, the heatbudget equation becomes

$$
\begin{aligned}
\rho_{s} C_{s} \Delta z \frac{d T}{d t}-b_{0} \dot{m}_{f}= & C_{l} \cdot\left[\begin{array}{c}
\rho_{l} \mathrm{RR} \\
M_{\text {in }}
\end{array}\right] \cdot\left(\left[\begin{array}{c}
T_{\text {rain }} \\
T_{\text {in }}
\end{array}\right]-T\right)-b_{1} \Delta V_{i}+\Delta\left(k_{\text {eff }} \frac{d T}{d z}\right) \\
& +\left[\begin{array}{c}
K \downarrow-K \uparrow \\
\left|S_{\text {in }}\right|
\end{array}\right] \cdot\left(1-e^{-\Delta z / \lambda}\right)+\left\{b_{2} V_{l, \text { sfc }}-F_{H}+F_{\text {IR,in }}-\varepsilon_{s} \sigma T^{4}\right\},
\end{aligned}
$$

where each term starting from the top left represents 1) temperature tendency, 2) freezing, 3) advection of sensible heat by liquid, 4) vapor sublimation/deposition processes, 5) thermal conduction, 6) solar heating, and 7) latent and sensible heat fluxes and net longwave radiation.

At each time step, every term on the right side of Eq. (2) is computed based on the conditions at the start of the time step, and the results are saved as separate forcing terms. Prior to the compaction stage, all forcing terms on the right-hand side are summed to find the total temperature change and subsequent melting/freezing on the left-hand side (see the online supplemental material).

The human factors modeled in the second stage of each time step are described next.

\section{Human processes modeled in PISTE}

\section{a. Compaction stage}

During the second part of each time step, a snow layer can be compacted if there is sufficient weight above it, as quantified by downward imposed normal stress $\sigma_{w}$. Each layer has strength, or a normal failure stress $\sigma_{F}$, which is approximated as a function of snow density $\rho_{s}$, based upon the axial compressive stress data of Mellor (1975):

$$
\sigma_{F}=\sigma_{F, \text { ref }} \exp \left(\rho_{s} / \rho_{s, \text { ref }}\right),
$$

where $\left(\sigma_{F, \text { ref }}, \rho_{s, \text { ref }}\right)=\left(0.2 \mathrm{kPa}, 58.7048 \mathrm{~kg} \mathrm{~m}^{-3}\right)$ for $\rho_{s} \leq$ $500 \mathrm{~kg} \mathrm{~m}^{-3}$ or $\sigma_{F} \leq 1000 \mathrm{kPa}$ and $\left(\sigma_{F, \text { ref }}, \rho_{s, \text { ref }}\right)=$ $\left(56.234 \mathrm{kPa}, 173.7178 \mathrm{~kg} \mathrm{~m}^{-3}\right)$ for $\rho_{s}>500 \mathrm{~kg} \mathrm{~m}^{-3}$ or $\sigma_{F}>$ $1000 \mathrm{kPa}$. Equation (3) applies to dry snow but has been validated by measurements at snow temperatures ranging from $-10^{\circ}$ to $-3^{\circ} \mathrm{C}$ [i.e., relatively warm temperatures like those measured during RC Whistler intensive observation period (IOP)], to within one order of magnitude (Mellor 1975).

If the imposed normal load on the snow layer $\sigma_{w}$ exceeds the failure stress $\sigma_{F}$, the snow layer will be compacted. As $\Delta z$ decreases, the density, and therefore strength $\sigma_{F}$, increases. Eventually, the strength matches the imposed stress $\left(\sigma_{F}=\sigma_{w}\right)$, at which point the compaction stops. To find the final compressed snow density, Eq. (3) is inverted to give

$$
\rho_{s}=\rho_{s, \text { ref }} \ln \left(\sigma_{F} / \sigma_{F, \text { ref }}\right) .
$$

We assume 1) there is an imposed stress due to skiers and snow weight at every time step, 2) total imposed stress consists of only the static component (only weight is considered; accelerations are neglected), 3) compacting of any one layer occurs if and only if $\sigma_{w}>\sigma_{F}$ for that layer, 4) compacting reduces only the size of the pore space and no liquid water is lost from the layer, 5) the new layer thickness is

$$
\Delta z_{\text {new }}=\left(\rho_{s, \text { old }} / \rho_{s, \text { new }}\right) \Delta z_{\text {old }},
$$

and 6) the compacting is approximately instantaneous. We define the change in thickness as

$$
\Delta z_{c}=\Delta z_{\text {old }}-\Delta z_{\text {new }}=\Delta z_{\text {old }}\left[1-\left(\rho_{s, \text { old }} / \rho_{s, \text { new }}\right)\right] .
$$

After all the natural physical processes have altered the state and strength of each snow layer, they are each tested for compaction, starting from the top layer. The skier/snowboarder causes a surface stress of $\sigma_{w, \text { sfc }} \approx$ $1.9 \mathrm{kPa}$. This value uses the weight of an adult female, 
$\sim 59 \mathrm{~kg}$, divided by the cross-sectional area of her snowboard, $\sim 0.304 \mathrm{~m}^{2}$, multiplied by gravitational acceleration, $9.8 \mathrm{~m} \mathrm{~s}^{-2}$. Heavier skiers/snowboarders generally use larger skis or snowboards, resulting in nearly the same imposed normal stress.

We can also impose occasional special events such as passage of a grooming machine (known as a snowcat) with $\sigma_{w, \text { sfc }} \approx 5.9 \mathrm{kPa}$, found as the average normal stress from three different snowcat models. This is close to the value found by Olefs and Lehning (2010) of $\sigma_{w, \mathrm{sfc}} \approx$ $5.6 \mathrm{kPa}$ using one snowcat having mass per unit area $0.57 \mathrm{~kg} \mathrm{~m}^{-2}$. Grooming is discussed further in section $4 \mathrm{~b}$. The $\sigma_{w, \text { sfc }}$ values are approximations, since dynamic loads (skiers turning or snowcats accelerating) are neglected. Future versions of PISTE might also vary the timing of the passage of skiers.

The incremental stress associated with the weight of any single snow layer is

$$
\Delta \sigma_{w}=g^{\prime} \rho_{s} \Delta z
$$

where $g^{\prime}=0.0098 \mathrm{kPa}\left(\mathrm{kg} \mathrm{m}^{-2}\right)^{-1}$ includes the gravitational acceleration and unit conversions. Each layer is assumed to have an imposed normal stress proportional to the weight of all the layers above plus the weight of the surface objects:

$$
\sigma_{w}=\sigma_{w, \mathrm{sfc}}+\sum_{\text {all layers above }} \Delta \sigma_{w} .
$$

As any layer compacts, all the layers above move downward, causing potential energy to be converted into heat. This heat is very small and can be neglected.

\section{b. Grooming of ski piste by snowcats}

When a ski piste is groomed by a snowcat, the main objective is to increase the density by compaction (Fauve et al. 2002). This is mainly achieved with 1 ) the weight of the snowcat $(6000-12000 \mathrm{~kg}) ; 2)$ the tiller, which churns the snow over some operator-defined depth; and 3) the finisher, which levels the snow following the tiller.

When the tiller is operated at high speeds, the snow grains on average become smaller and rounder (Fauve et al. 2002). The grain-size distribution is increased by breaking up larger grains and dendrites. Following this, compaction increases the density since smaller grains will fill pore space that could not previously be filled with larger crystals, and the snow grains can be closer to one another. A large grain-size distribution is also preferable for snow grain bonding and sintering, which hardens the snowpack (ideal for racing), since there is a larger contact area between grains where bonds can grow.

It takes an hour or more for snow grains to bond and gain strength after tilling (Fauve et al. 2002), meaning the assumptions regarding strength in section $4 \mathrm{a}$ are not valid immediately following grooming. In fact, it takes about $8 \mathrm{~h}$ for the piste to reach optimal strength (Fauve et al. 2002). However, grooming usually happens overnight and many hours pass before the piste is skied upon, so this is not a practical problem, but is a constraint on PISTE.

Fauve et al. (2002) found that compression produced by a snowcat decreases as driving speed increases. Ski pistes are usually groomed to a depth of $10-15 \mathrm{~cm}$, and for a harder snow surface (e.g., for racing), the snowcat moves very slowly $\left(3-5 \mathrm{~km} \mathrm{~h}^{-1}\right)$ with the tillers moving very rapidly (R. MacLeod 2010, personal communication).

PISTE models this mechanical process in the following way.

\section{c. Mixing and merging of snow layers in PISTE}

The following two occasional events can require snow layers to combine their physical states. First, in mixing, rotary tillers on the grooming machine churn the top layers of snow (as discussed in section 4b), creating a mixed region, which we assume has homogenized snow characteristics. Second, in merging, if melting and/ or sublimation remove the majority of ice mass from any one snow layer, allowing it to be compacted to a thickness much smaller than neighboring layers, then this thin layer can be computationally merged with the neighboring lower layer to create a single layer that is thick enough to avoid numerical instability [we used a merging threshold of $\Delta z=0.8 \times 10^{-3} \mathrm{~m}$ in our case study (see section $5 \mathrm{c}$ )]. Both of these processes require conservation of ice mass, liquid mass, and heat.

For the mixing event, assume that the depth of mixing is known from the design and operational settings on the snowcat grooming machine. Snow layers can be counted from the top down to find the deepest layer that is mixed. Rounding the mixing depth up to an integer number of $n$ layers gives the total mixed region depth as

$$
\Delta z_{\text {total }}=\sum_{j=1}^{n} \Delta z_{j}
$$

where $\Delta z_{j}$ is the thickness of the $j$ th snow layer that participates in mixing.

Conservation of ice and liquid water mass give the volume fractions of ice $f_{i}$ and liquid water $f_{l}$ as

$$
f_{i, \text { mixed }}=\frac{1}{\Delta z_{\text {total }}} \sum_{j=1}^{n} \Delta z_{j} f_{i, j}
$$

and

$$
f_{l, \text { mixed }}=\frac{1}{\Delta z_{\text {total }}} \sum_{j=1}^{n} \Delta z_{j} f_{l, j} .
$$


These volume fractions are used to find the new mixedlayer snow density $\rho_{s \text {,mixed }}$ and specific heat $C_{s, \text { mixed }}$ [see Eqs. (4) and (5) in the online supplemental material]. Heat conservation then gives the temperature of the mixed layer:

$$
T_{\text {mixed }}=\frac{1}{C_{s, \text { mixed }} \Delta z_{\text {total }}} \sum_{j=1}^{n} \Delta z_{j} C_{s, j} T_{j} .
$$

These mixed values are then assigned to be the new state of all the individual layers that were mixed, where each layer is assumed to still exist in the model with its original thickness from before the mixing. The final step is to reapply the compacting stage to modify each snow layer if needed, so that it can support itself plus any imposed load.

Merging uses the same equations as mixing, except that 1) only two layers are involved, 2) the thinnest layer that required merging is deleted afterward, and 3) the next layer down takes on the new total thickness $\Delta z_{\text {total }}$ with the new states as given in the previous paragraph. For the special case of the bottom layer of the whole snow column becoming thinner than the merging threshold, it is merged with the layer above. The final step is to reapply the compacting stage.

PISTE is tested next for a clear-sky case study.

\section{Clear-sky case study}

We prescribe measurements from a clear-sky IOP (18-22 February 2010, during the Winter Olympics) as boundary conditions, to evaluate simulations of snowsurface temperature made by PISTE.

\section{a. Field site, instrumentation, and weather conditions}

Meteorological data were collected at RC Whistler $\left(50^{\circ} 5^{\prime} 16^{\prime \prime} \mathrm{N}, 122^{\circ} 57^{\prime} 41^{\prime \prime} \mathrm{W}\right)$, a site on Whistler Mountain, British Columbia, Canada (see Fig. 3). RC Whistler is on a ski piste in the subalpine of a recreational ski area.

A full summary of instruments is given in Table 1. Two instrument platforms were deployed: a suspended platform over the ski piste and a 10-m tower (Fig. 4). Instruments were placed on the suspended platform (denoted "a" in Fig. 4) to capture the behavior of the snow surface and its interactions with the atmosphere. The platform held an Apogee Precision Infrared Radiometer (IRR-P) to remotely measure the snow-surface temperature, a Kipp \& Zonen Net Radiometer (CNR1), an in situ Campbell Scientific HygroClip temperature and humidity probe $\mathrm{S} 3$ with operating temperatures from $-50^{\circ}$ to $50^{\circ} \mathrm{C}$ (HC-S3-XT), and a Campbell Scientific Sonic Ranging Sensor (SR50) to remotely measure the snow depth. The platform was held by two parallel steel

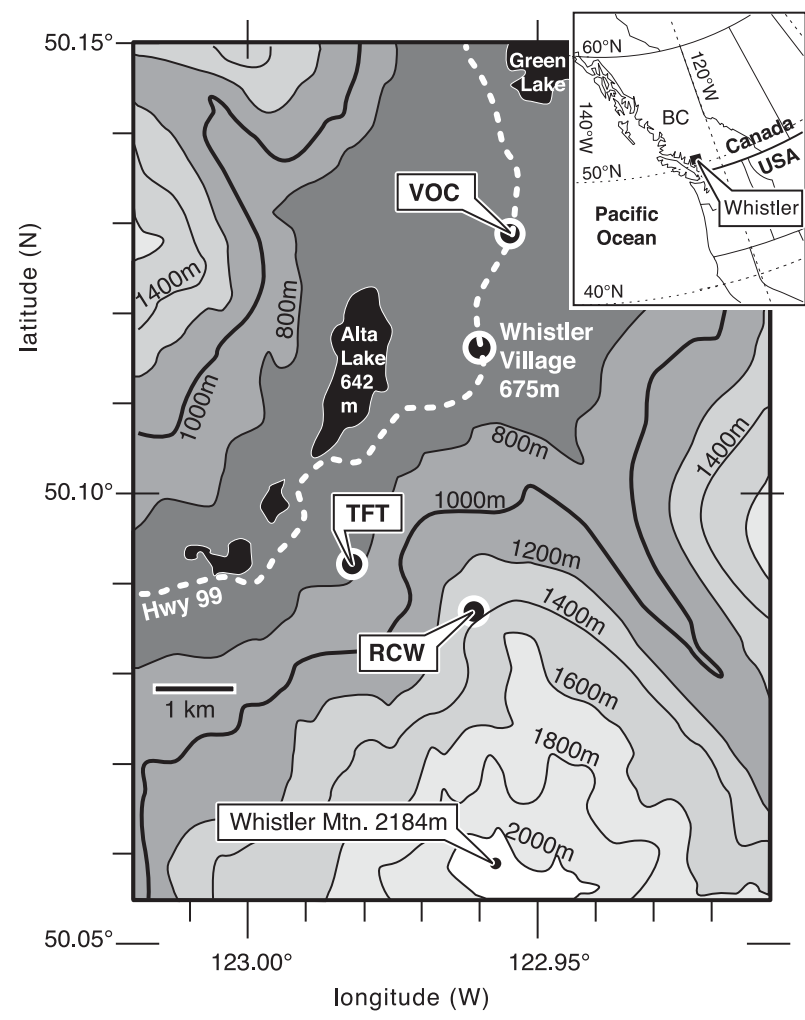

FIG. 3. Map showing the locations of RC Whistler (RCW), the Environment Canada ceilometer site (TFT), and Environment Canada manual observation site (VOC). Also shown is Whistler Village, nearby lakes, and Whistler Mountain peak. Elevation contours are plotted every $200 \mathrm{~m}$ MSL.

cables, at a distance of $9 \mathrm{~m}$ above the ski piste when there was no snowpack, as measured by the sonic ranger. This was high enough for skiers and grooming equipment to pass safely underneath with $1-2 \mathrm{~m}$ of snow on the ground.

The tilted 10-m instrument tower included a Gill 3D Ultrasonic Anemometer (WindMaster) and an OTT Particle Size Velocity (Parsivel) disdrometer at the top (denoted "b" in Fig. 4) and a second Campbell Scientific HC-S3-XT temperature and humidity probe at the bottom (denoted "c" in Fig. 4). The instruments at the top and the bottom of the tower were slightly over 10 and $2 \mathrm{~m}$ above bare ground, respectively. All data from RC Whistler were sampled at a frequency of $2 \mathrm{~s}$ then averaged and recorded by either a CR1000 or CR3000 datalogger from Campbell Scientific every $10 \mathrm{~s}$.

During the IOP, a strong upper-level ridge that turned into an upper-level closed high dominated the west coast of British Columbia, bringing unseasonably warm and sunny conditions to the southwest coast, including Whistler. Clear skies were confirmed by downwelling shortwave radiation measurements from the suspended platform and were further confirmed by a nearby 
TABLE 1. Instrumentation of the automatic weather station at RCW from March 2008 to April 2010. Location "a" is a suspended instrument platform, "b" is top of tower, "c" is bottom of tower, and "ground" is earth-snowpack interface. See Fig. 4 for locations. During RCW IOP, the suspended platform height varied between 7.9 and $8.0 \mathrm{~m}$ above the snow surface.

\begin{tabular}{|c|c|c|c|}
\hline Measurement & Instrument & Location & Comment \\
\hline Air temperature & $\begin{array}{l}\text { Campbell Scientific } \\
\text { HC-S3-XT }\end{array}$ & a & $\begin{array}{l}\text { Contained in RM Young Multi-Plate Radiation } \\
\text { Shield (41003-X) (unaspirated) }\end{array}$ \\
\hline Relative humidity & $\begin{array}{l}\text { Campbell Scientific } \\
\text { HC-S3-XT }\end{array}$ & a & $\begin{array}{l}\text { Contained in RM Young Multi-Plate Radiation } \\
\text { Shield (41003-X) (unaspirated) }\end{array}$ \\
\hline Net radiation & Kipp \& Zonen CNR1 & a & $\begin{array}{l}\text { Measures upwelling and downwelling, shortwave } \\
\text { and longwave radiation individually }\end{array}$ \\
\hline Snow-surface temperature & Apogee IRR-P & $\mathrm{a}$ & - \\
\hline Snow depth & Campbell Scientific SR50 & a & - \\
\hline Atmospheric pressure & RM Young 61205V & a & Inside datalogger enclosure \\
\hline Wind speed and direction & Gill Windmaster & $\mathrm{b}$ & 3D ultrasonic anemometer \\
\hline Precipitation rate and phase & OTT Parsivel disdrometer & $\mathrm{b}$ & - \\
\hline Air temperature & $\begin{array}{l}\text { Campbell Scientific } \\
\text { HC-S3-XT }\end{array}$ & $\mathrm{c}$ & $\begin{array}{l}\text { Contained in Met-One Model } 077 \text { Motor } \\
\text { Aspirated Radiation Shield }\end{array}$ \\
\hline Relative humidity & $\begin{array}{l}\text { Campbell Scientific } \\
\text { HC-S3-XT }\end{array}$ & $\mathrm{c}$ & $\begin{array}{l}\text { Contained in Met-One Model } 077 \text { Motor } \\
\text { Aspirated Radiation Shield }\end{array}$ \\
\hline Ground-snow interface temperature & $5 \times$ Type $E$ thermocouples & Ground & Put in place prior to snowfall \\
\hline
\end{tabular}

Vaisala Laser Ceilometer (CT25K) located at the bottom of the ski piste $\left(50^{\circ} 05^{\prime} 31^{\prime \prime} \mathrm{N}, 122^{\circ} 58^{\prime} 00^{\prime \prime} \mathrm{W}\right.$, elevation $782 \mathrm{~m}$ MSL; denoted TFT in Fig. 3) just over $1 \mathrm{~km}$ to the west of RC Whistler, as well as manually observed hourly data (Environment Canada 2012) from an Environment Canada automated weather station location $\left(50^{\circ} 07^{\prime} 48^{\prime \prime} \mathrm{N}\right.$, $122^{\circ} 57^{\prime} 55^{\prime \prime} \mathrm{W}$, elevation $657.8 \mathrm{~m}$ MSL; denoted VOC in Fig. 3).

Manual weather observations were not possible at RC Whistler during the IOP because of Olympics security; however, they were recorded for two winters prior to the Olympics. Further details of instrumentation and data analysis are given in the online supplemental material, including a discussion of snow-surface temperature measurements.

\section{b. Boundary conditions for PISTE}

PISTE was driven at the upper boundary by meteorological measurements from RC Whistler IOP of downwelling shortwave and longwave radiation, 2-m air temperature and relative humidity, and 10-m horizontal wind speed (Fig. 5). Atmospheric pressure (not plotted) was used in the thermodynamics for the turbulent heat fluxes and had a range of only $0.8 \mathrm{kPa}$ throughout $\mathrm{RC}$ Whistler IOP.

Despite cloud-free skies, local sunrise at RC Whistler was delayed by a couple of hours because of shading by nearby trees and complex terrain (Fig. 5, top). Howard and Stull (2011) modeled the shading of the snow surface due to trees and "objects" at RC Whistler and found that the timing error at sunrise and sunset between solar radiation received at instrument platform height versus the snow surface beneath is about $30 \mathrm{~min}$.
However, they also state that the resolution of their treeand object-height measurements (every $5^{\circ}$ azimuth) could have been better, making the timing error shorter. Hence, we neglect this error and use measurements from suspended platform height, since the frequency of input boundary conditions to PISTE is $30 \mathrm{~min}$ (discussed later in this section).

Downwelling longwave radiation measurements are corrected for solar heating of CNR1 (Michel et al. 2008; Philipona et al. 1995), then further corrected from instrument platform height (see Fig. 4) to the snow

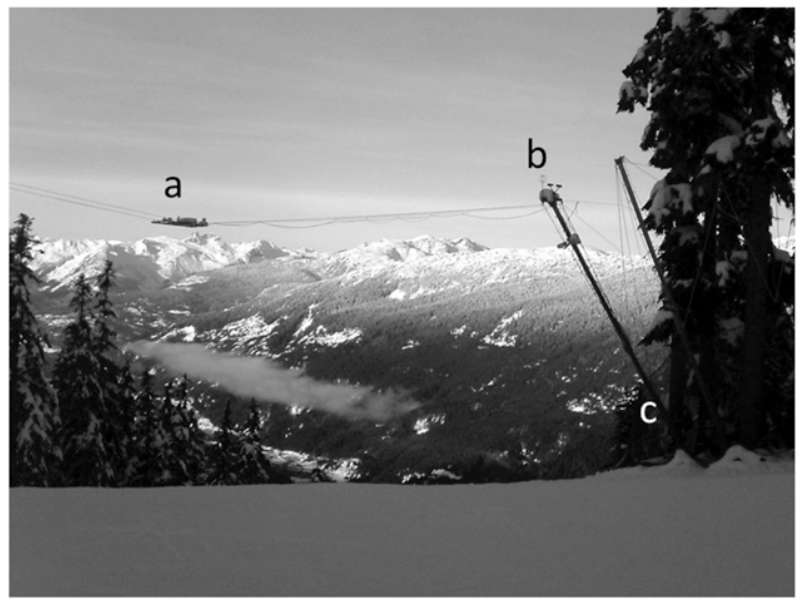

FIG. 4. Photograph at RCW showing suspended instrument platform above ski piste (indicated by "a"), instruments at top of tower to the right (indicated by " $b$ "), and instruments at bottom of tower to right (indicated by "c"'). Full summary of instruments and placement is in Table 1 and in the text. (Photograph by the lead author, looking approximately west, Whistler Mountain, British Columbia, 2008). 

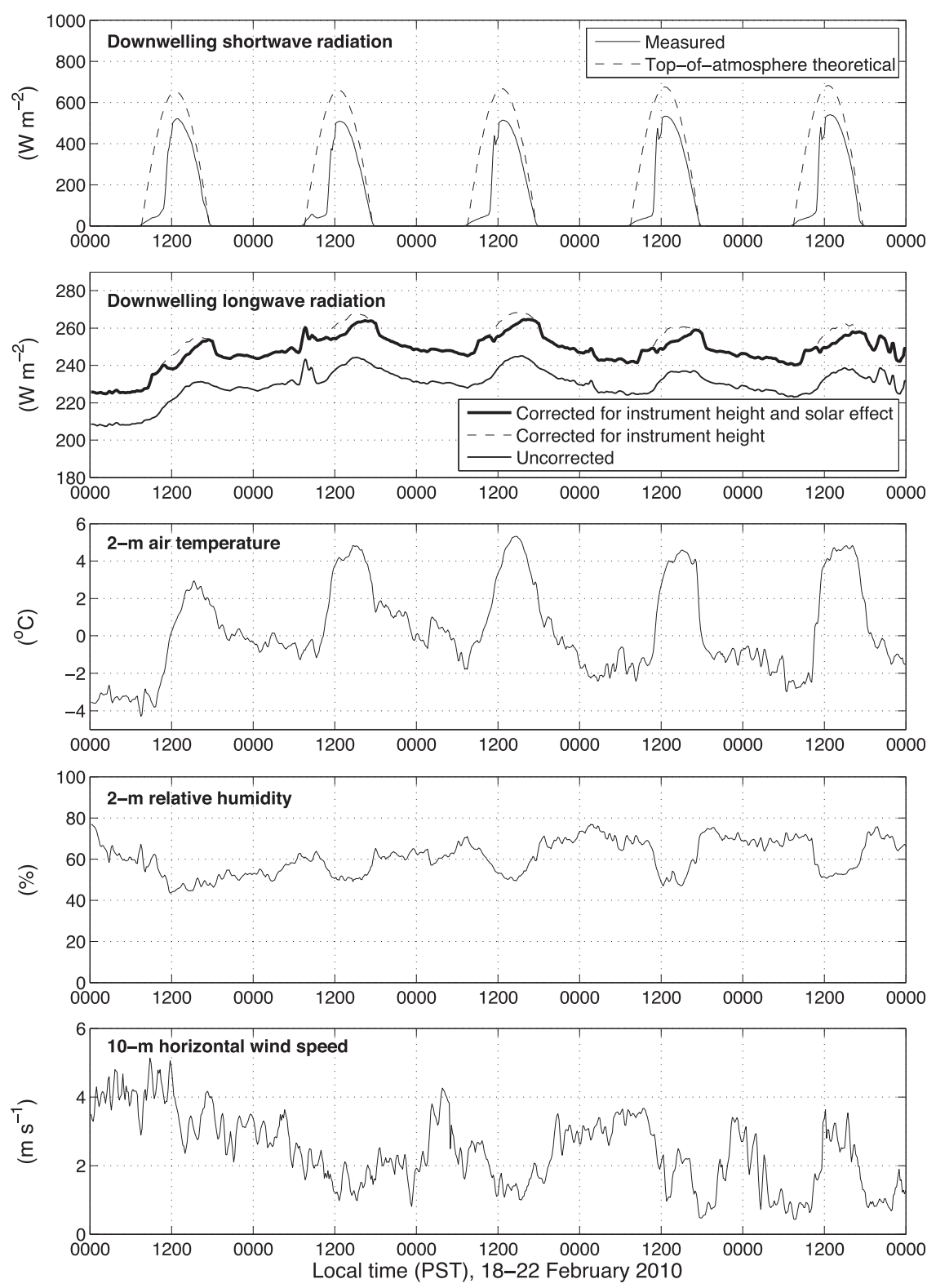

FIG. 5. Upper-boundary conditions for PISTE from RCW IOP (from top to bottom): 1) measured (solid line) and theoretical (dashed line) top-of-atmosphere downwelling shortwave radiation; 2) measured downwelling longwave radiation from the CNR1 net radiometer: uncorrected instrument-platform-height measurement (thin solid line), corrected from instrument height to snow surface (dashed line), and further corrected for solar heating of CNR1 (thick solid line); 3) 2-m air temperature from HC-S3-XT; 4) 2-m relative humidity from HC-S3-XT; and 5) 10-m horizontal wind speed from the 3D sonic anemometer.

surface, taking into consideration thermal emissions from nearby trees (Howard and Stull 2013a,b). Further details of the latter correction are given in the online supplemental material.

The 2-m air temperature and relative humidity and $10-\mathrm{m}$ wind speed are used to estimate the turbulent fluxes of sensible and latent heat between the snow surface and the atmosphere. During the IOP the snow depth varied by only $0.1 \mathrm{~m}$, so we did not adjust the measurement height or the observations. If snow depth varies greatly during future observation periods at RC Whistler or other locations, we suggest adjusting the measurement heights so that they are consistently 2 and $10 \mathrm{~m}$ above the snow surface, to calculate fluxes. The aim is that PISTE will eventually be driven by numerical weather prediction (NWP) output, which 

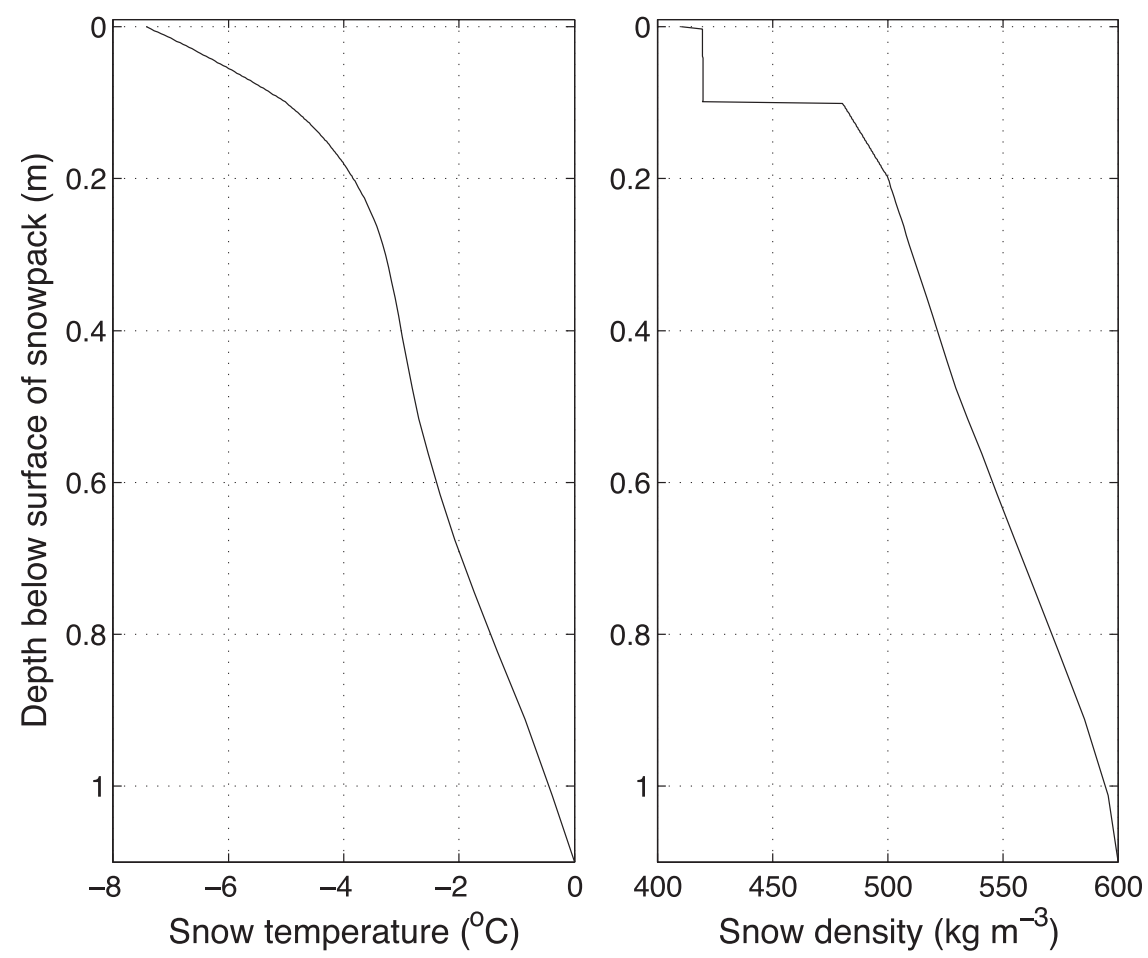

FIG. 6. Initial snowpack (left) temperature and (right) density profiles for PISTE, taken from hour 72 of the spinup. Valid local time for these profiles is 0300 Pacific Standard Time (PST; = $\mathrm{UTC}+8 \mathrm{~h})$.

means turbulent fluxes can be obtained directly from an NWP model.

The earth-snow interface of a snowpack is often assumed to be at $0^{\circ} \mathrm{C}$ because of geothermal heat flux along with heat stored from the summer (McClung and Schaerer 2006). The mean output from five type $E$ (chromel-constantan) thermocouples at the base of the snowpack at RC Whistler in the 2009/10 winter season was $0.06^{\circ} \pm 0.5^{\circ} \mathrm{C}$. For these reasons, a value of $0^{\circ} \mathrm{C}$ is used for the ground temperature for this case study.

Top boundary conditions were smoothed with a 30-min running average and then sampled every $10 \mathrm{~min}$. PISTE interpolates the boundary conditions to the time step. In addition to smoothing out measurement noise and shortlived turbulence, this approach is designed to mimic NWP output, that is, a forecast of the mean state of variables, from typically every $15 \mathrm{~min}$ to $1 \mathrm{~h}$. This anticipates future applications of PISTE, driven by NWP output to give snow-surface condition forecasts.

\section{c. Initial conditions for PISTE}

Vertical profiles of temperature, density, and liquid water content are required by PISTE as initial conditions. A high-density, hard snowpack at RC Whistler, along with skier safety, prevented measurements of the snowpack interior, so the initial temperature and density profiles for this case study (Fig. 6) were found by spinning up the PISTE model.

Prior to the spinup, the model snowpack was set to be completely dry with an isothermal temperature profile of $T=-5^{\circ} \mathrm{C}$. The initial snow density profile for the spinup increases linearly from $\rho_{s}=400 \mathrm{~kg} \mathrm{~m}^{-3}$ at the snow surface to $\rho_{s}=600 \mathrm{~kg} \mathrm{~m}^{-3}$ at the bottom of the snow column. In general, snow density in alpine snowpacks increases with depth (McClung and Schaerer 2006), and the surface value of $\rho_{s}=400 \mathrm{~kg} \mathrm{~m}^{-3}$ is justified since it is close to the mean value of $\rho_{s}=441 \mathrm{~kg} \mathrm{~m}^{-3}$ measured at RC Whistler IOP (see the online supplemental material). We used the averaged measured snow depth from RC Whistler IOP, which was $1.1 \mathrm{~m}$, with vertical grid spacing of $\Delta z=2 \times 10^{-3} \mathrm{~m}$ in the top $20 \mathrm{~cm}$ of snow, increasing linearly to $\Delta z=0.1 \mathrm{~m}$ at the base of the snowpack, giving 132 snow layers. PISTE also begins all simulations with a snowcat grooming event.

Boundary conditions from 18 February 2010 were repeatedly input to PISTE every $24 \mathrm{~h}$ for nearly 4 days, with the aim of reaching a realistic initial state for simulating the subsequent 4 days, 19-22 February 2010 (Fig. 7). When summed over the whole day, there was a net heat input applied at the top boundary; hence, there was no expectation that the snow temperature profile would reach equilibrium. The temperature profile 


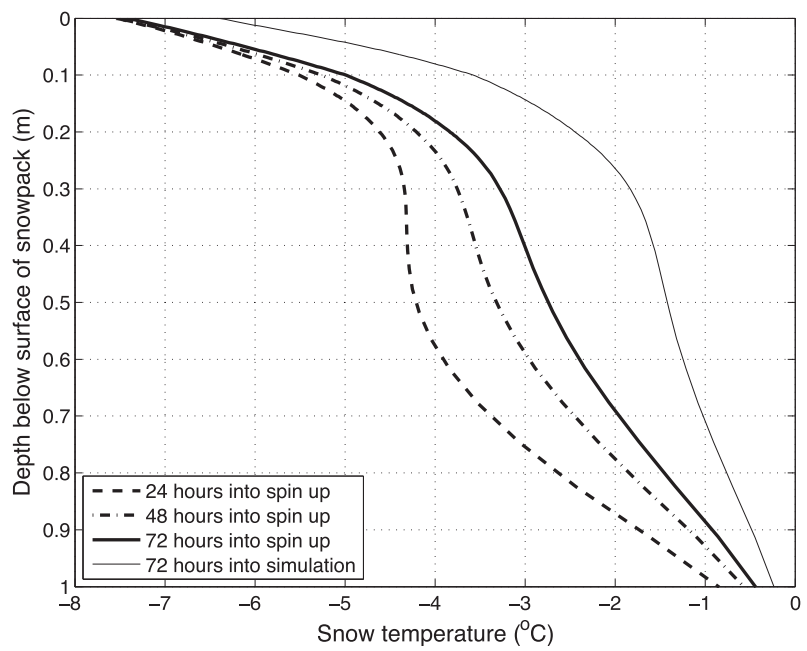

FIG. 7. Snowpack temperature profiles simulated by PISTE after 24,48 , and $72 \mathrm{~h}$ of spinup with repeated boundary conditions from 18 Feb 2010 at RCW. Valid local time is 0300 PST each day. Also plotted is the snowpack temperature profile valid at 0300 PST $22 \mathrm{Feb}$ 2010, $72 \mathrm{~h}$ into the PISTE simulation, demonstrating that the spinup was necessary. The 24- and 48-h snowpack temperature profiles from the simulation (not plotted) lie close to the 72-h simulation curve, only with slightly warmer near-surface temperatures.

after $72 \mathrm{~h}$ of spinup had the closest simulated snowsurface temperature to the measured value at 0300 PST 19 February 2010, our intended simulation start time, differing by $1.04^{\circ} \mathrm{C}$. Therefore, we chose this temperature profile and concurrent density and liquid water content profiles as the initial condition inputs for the PISTE case study. In Fig. 6, note the density mixed layer between the surface and $10-\mathrm{cm}$ depth due to the simulated grooming that occurred $2 \mathrm{~h}$ earlier at 0100 PST and the sublimation of ice at the snow surface since grooming, reducing the top layer snow density.

PISTE was initialized at 0300 PST 19 February 2010, and the simulation ended at 2100 PST 22 February 2010, with actual observed boundary conditions (Fig. 5) applied to the model during this period. The model ran stably for this $90-\mathrm{h}$ period (which took approximately $3 \mathrm{~h}$ to run on a dual-core Intel desktop computer) with a 1-s time step. The thinnest snow layer that could be modeled reasonably well is $\Delta z=$ $0.6 \times 10^{-3} \mathrm{~m}$. [For comparison, CROCUS modeled a $5 \times$ $10^{-2} \mathrm{~m}$ layer thickness with a 15 -min time step (Brun et al. 1989).] To avoid instability, whenever a layer becomes thinner than our merging threshold (see section $4 \mathrm{c}$ ) of $\Delta z=$ $0.8 \times 10^{-3} \mathrm{~m}$, it is merged into the layer below it.

Next, we make a detailed analysis of the 4-day simulation initialized at 0300 PST 19 February 2010.

\section{Results and discussion}

The simulated snow-surface temperature compares well with measured snow-surface temperature from RC

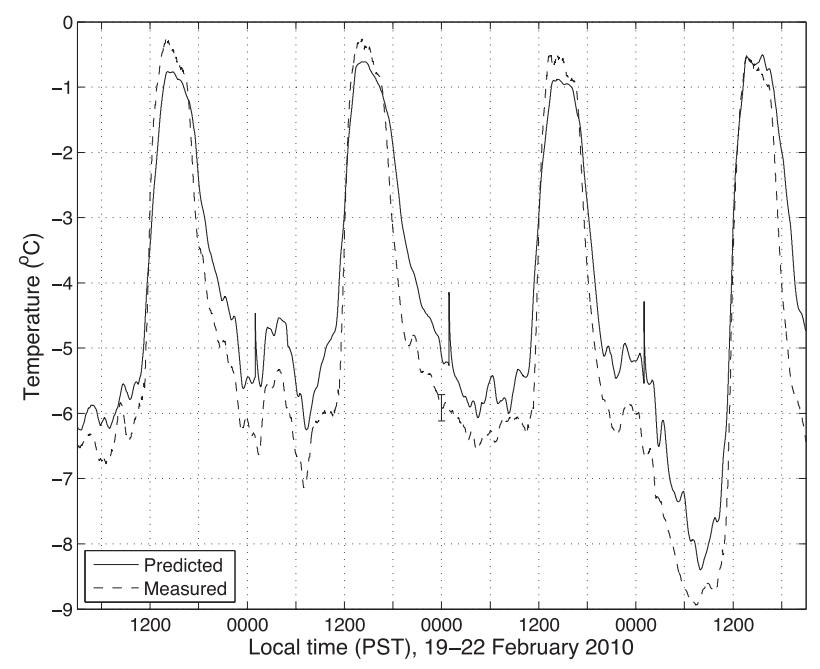

FIG. 8. Simulated and measured snow-surface temperature at RCW for 19-22 Feb 2010. Snow-surface temperature measurements are corrected for snow emissivity and background reflected longwave radiation. Apogee IR thermometer measurement accuracy of $\pm 0.2^{\circ} \mathrm{C}$ is shown by way of an error bar at 0000 PST $21 \mathrm{Feb}$ (the center of the time period shown). This error is constant throughout the observations. The short-period fluctuations in this simulation are due to the short-period boundary conditions imposed at model top, where these boundary conditions are from the actual field measurements.

Whistler IOP (Fig. 8), with a mean absolute error (MAE) of $0.75^{\circ} \mathrm{C}$ and a root-mean-squared error (RMSE) of $0.86^{\circ} \mathrm{C}$. The timing of the daytime snowsurface temperature peaks simulated by PISTE are accurate but are underestimated by a mean value of $0.5^{\circ} \mathrm{C}$, with the exception of 22 February 2010. Since ski waxes

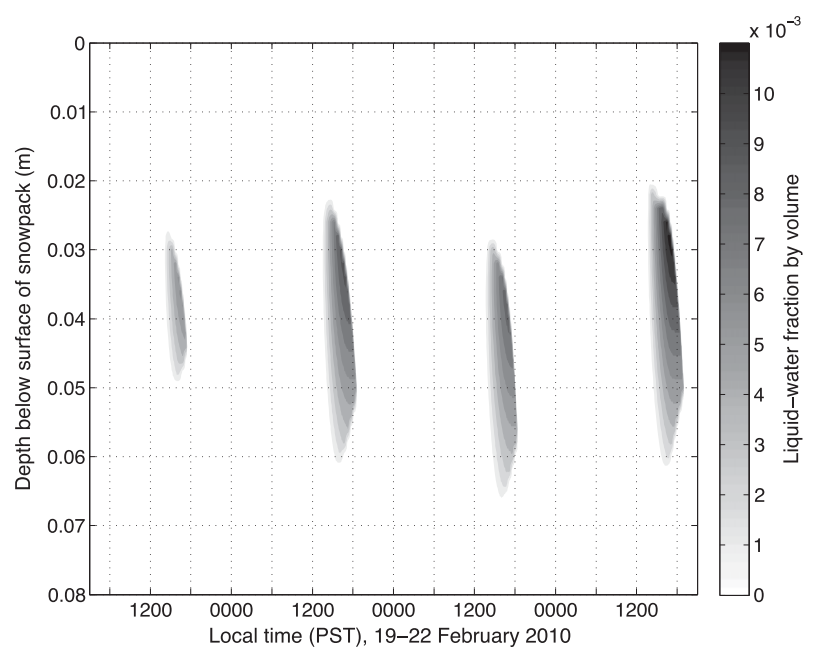

FIG. 9. The simulated evolution of the snowpack vertical liquid water fraction profile for RCW for 19-22 Feb 2010. The top $8 \mathrm{~cm}$ of snowpack is plotted every $5 \mathrm{~min}$. There was no liquid water content predicted deeper in the snowpack than this. 

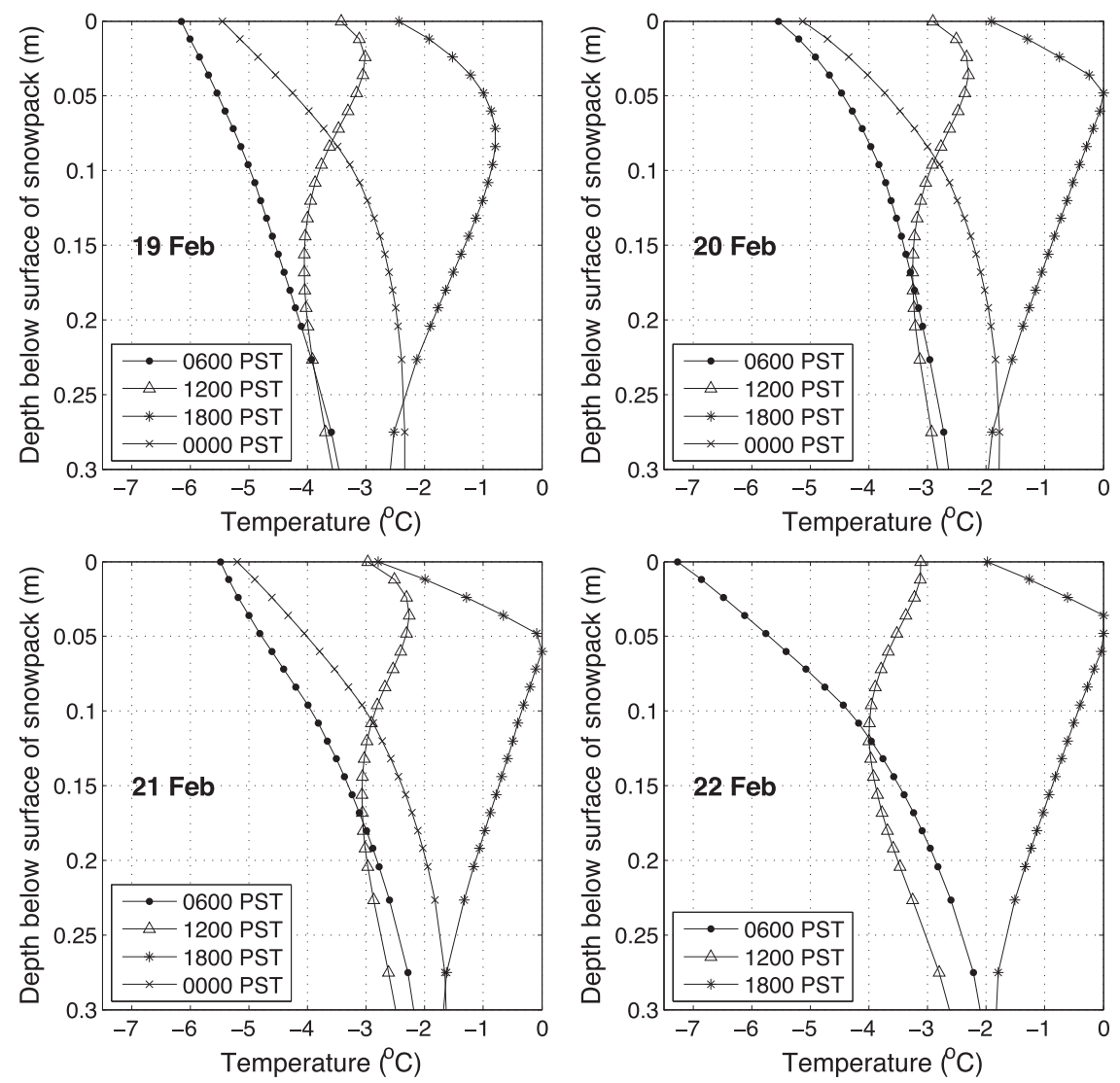

FIG. 10. Snowpack vertical temperature profiles simulated by PISTE at RCW for 19, 20, 21, and $22 \mathrm{Feb} 2010$ at 0600, 1200, 1800, and 0000 PST (local time). The simulation ran for $90 \mathrm{~h}$, so there is no 0000 PST profile on $22 \mathrm{Feb}$. The top $30 \mathrm{~cm}$ of the snowpack is plotted every five snow layers.

generally have a temperature range of several degrees within which they can be used, this error is acceptable for this application.

One contributing factor to daytime errors is that we use a constant snow-surface albedo of $a=0.81$ in PISTE. Future model enhancements should include parameterizing the albedo as a function of solar zenith angle. Also, snow albedo is dependent on snow grain size (Nolin and Dozier 2000), so modeling snow microstructure explicitly could allow a more complex parameterization. Solar absorption length and thermal conductivity could also benefit from explicit snow grain modeling. However, the PISTE model is not designed to predict snow microstructure.

Snow-surface temperature "spikes" appear in the PISTE output (Fig. 8) at 0100 PST every morning because of simulated mechanical grooming at this time, which mixes the warmer subsurface temperatures upward. Modeled snow-surface temperature recovers quickly from this since the snow density and therefore thermal conductivity are already high and do not change substantially because of the simulated grooming. This is discussed further in section $7 \mathrm{~b}$.

Within the snowpack, PISTE created subsurface liquid water each afternoon of the simulation (Fig. 9), between approximately 2 - and $6-\mathrm{cm}$ depth where the snowpack temperature is $0^{\circ} \mathrm{C}$ (not shown). This implies the presence of a radiation effect similar to that found in natural snowpacks [discussed in Brandt and Warren (1993); Matson and Brown (1989); Morstad et al. (2007); Warren and Wiscombe (1980)], of subsurface warming due to penetration of solar radiation coupled with IR cooling of only the snow surface. Snowpack vertical temperature profiles (Fig. 10) also illustrate this effect developing throughout the afternoon, with significant warming of the snowpack interior due to solar radiation penetration. Regrettably, the modeled liquid water content could not be validated by measurements. Nonetheless, this modeled behavior gives us confidence that PISTE performs appropriately.

On each day, the model melt region (made up of multiple model layers; Fig. 9) reduces in thickness as the 

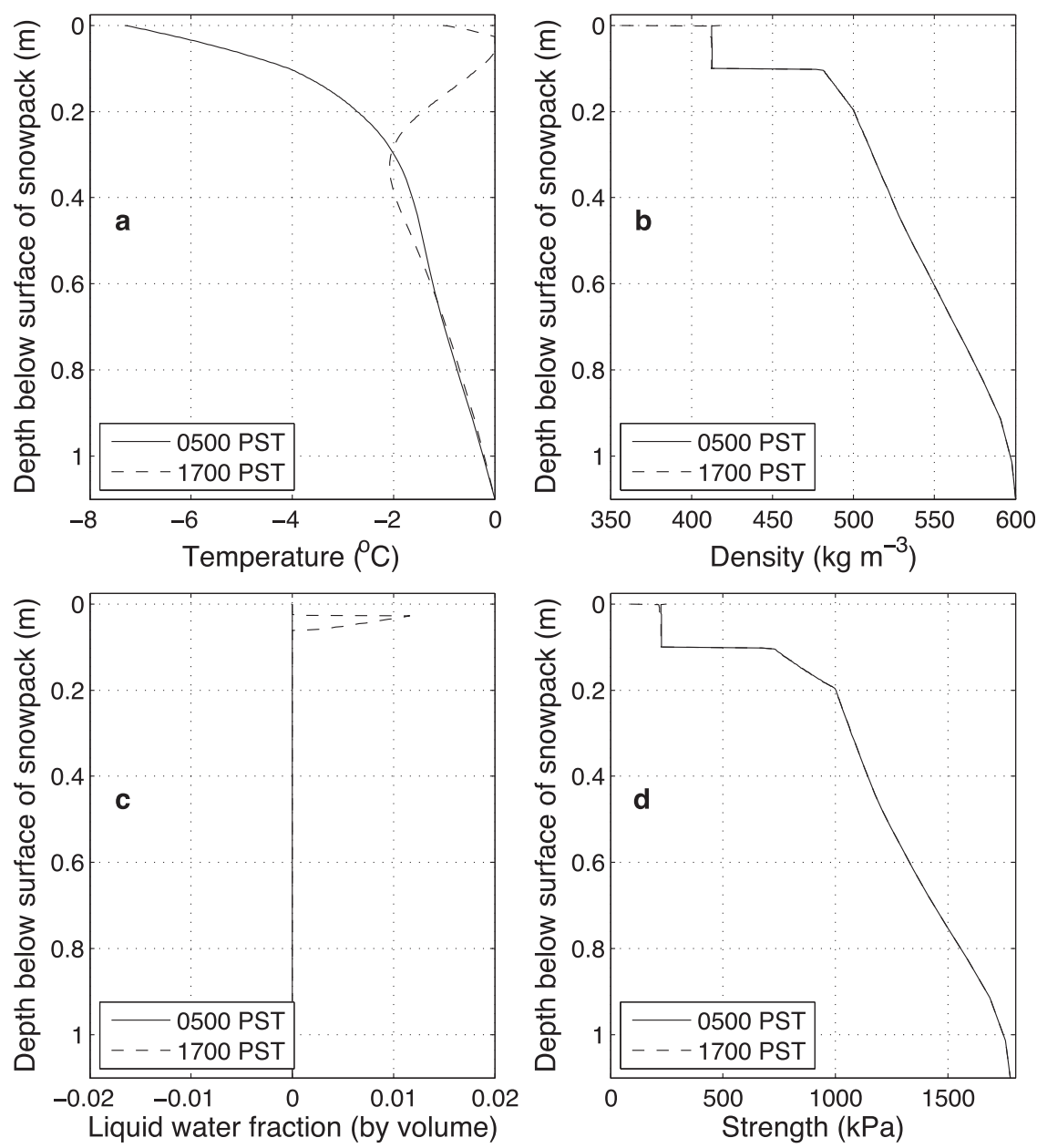

FIG. 11. Snowpack vertical profiles of (a) temperature, (b) density, (c) liquid water fraction, and (d) compaction strength, simulated by PISTE, at 0500 and 1700 PST 22 Feb 2010 for RCW. Grooming occurred at 0100 PST each day down to 10-cm depth.

solar radiation and air temperature decreases throughout the afternoon, and warmer snow-layer temperatures are conducted away from the melt region toward the surface, allowing refreezing. Similarly, at the bottom of the melt region, as the solar radiation penetrates less during the afternoon, we observe refreezing. There is an increase in liquid water content near the top of the melt region throughout the afternoon, at the depth where the time-integrated net heating is the highest.

Figure 11 shows vertical profiles of temperature, density, liquid water fraction, and compaction strength in the early morning (0500 PST) and just before sunset (1700 PST) on 22 February 2010 (the last simulation day) for the whole depth of the snowpack. The early morning temperature profile indicates strong surface IR cooling that has occurred overnight, with the cooling conducted down into the snowpack interior. The late afternoon profile shows the subsurface warming as a result of the radiation effect discussed earlier.
Snow density and compaction strength are directly related in PISTE (see section 4a), hence the similar profile shapes. As with the initial density profile, a constant density (and strength) region can be seen between the surface and 10-cm depth due to simulated mechanical grooming. The early morning profile has a very slight increase in density in the top snow layer, since the latent heat flux was negative (downward) during the morning of 22 February 2010 (Fig. 12), so ice (frost) was deposited in the top layer. During the afternoon, the latent heat flux was positive and the top layer sublimated ice, reducing its density and strength. The trend of each heat flux in Fig. 12 is similar for every day of the simulation, except this is the only day that the latent heat flux became negative.

The liquid water fraction was zero throughout the snowpack for the early morning profile on 22 February 2010 , since the subsurface melt region from the previous day had refrozen during the night. However, the 
subsurface melt region that developed in the afternoon of 22 February 2010 can be seen at 1700 PST in Fig. 11c.

At nighttime, the simulated snow-surface temperature has a small warm bias on the order of $1^{\circ} \mathrm{C}$ (Fig. 8). The correction to nighttime downwelling longwave radiation measurements was an approximation, not based on measurements as with the daytime correction.

Snow-surface temperature measurement errors are discussed in the online supplemental material (and include a correction for snow-surface emissivity and reflected "background" longwave radiation). The potential presence of dew and/or frost on CNR1 (also discussed in the online supplemental material) would result in erroneously larger longwave radiation measurements, since water is a strong absorber of IR radiation, meaning the temperature of the liquid water or ice would be measured rather than the clear, colder sky. We currently have no way to confirm this, but our analysis suggests it is possible that there was dew/frost on CNR1 at nighttime, contributing to the nighttime errors observed.

Constant values are used for the daytime and nighttime height correction to the downwelling longwave radiation measurements at RC Whistler (Howard and Stull 2013a,b; also see the online supplemental material). This will not capture the measurement variance completely since downwelling longwave radiation varies with air temperature and solar radiation, among other variables. Future work developing a diurnally varying correction might lead to a more accurate snow-surface temperature simulation.

\section{Conclusions}

\section{a. Summary}

A one-dimensional numerical snowpack model, PISTE, has been developed to make forecasts of snow temperature and liquid water content for a groomed ski piste. The model solves the heat-, liquid water-, and icebudget equations and incorporates human factors such as the weight of skiers frequently traversing the ski piste and grooming machines churning and compacting the top of the snowpack daily. To the authors' knowledge, this is the first snowpack model to do so. The model is applied to a clear-sky case study during the 2010 Winter Olympics to simulate snow-surface temperature and liquid water content, two variables important for the preparation of fast skis for racing.

Boundary conditions at the snow surface are prescribed from meteorological measurements made during the 5-day, clear-sky observation period (18-22 February 2010) at RC Whistler. Downwelling longwave radiation measurements were corrected from instrument

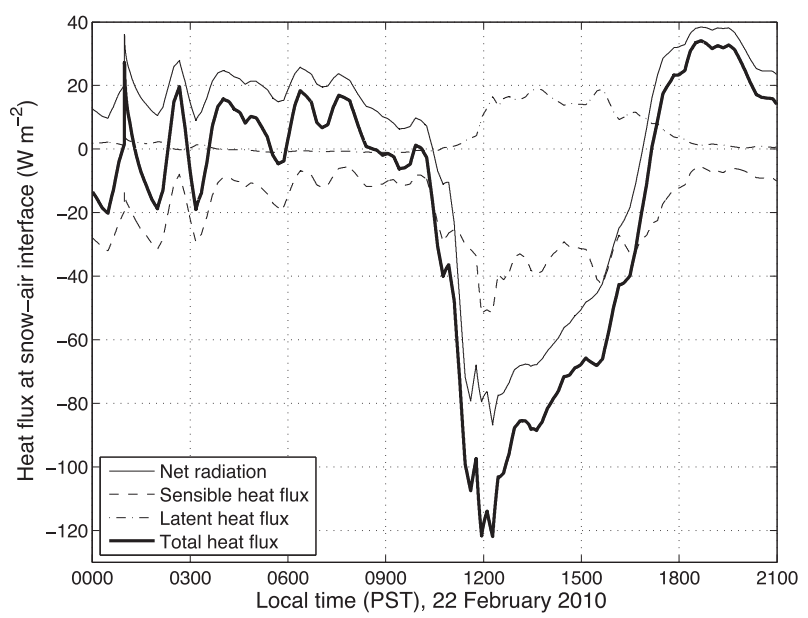

FIG. 12. Net radiation $F_{\text {net }}$, sensible heat flux $F_{H}$, latent heat flux $F_{E}$, and total surface heat flux $\left(=F_{\text {net }}+F_{H}+F_{E}\right)$ modeled by PISTE for $22 \mathrm{Feb} 2010$. Note that the latent heat flux is very slightly negative during the early morning, and the sharp discontinuity at 0100 PST is a result of simulated grooming. The model run ended at 2100 PST. Again, short-period fluctuations in these curves are due to the imposed top boundary conditions from the field observations.

height to the snow surface and for solar heating of CNR1.

Initial conditions were estimated by spinning up the model over $\sim 4$ days using repeated boundary conditions from 18 February 2010. The final choice of initial profiles of temperature, density, and liquid water content were selected from within the spinup based on the time that the simulated snow-surface temperature was closest to the observed snow-surface temperature at the case study initialization time.

A 4-day PISTE simulation was made for RC Whistler from 19 to 22 February 2010. The snow-surface temperature was well simulated (see Fig. 8) with an MAE of $0.75^{\circ} \mathrm{C}$ and an RMSE of $0.86^{\circ} \mathrm{C}$ for RC Whistler IOP. These errors are acceptable for the application of preparing fast race skis. We were unable to assess the accuracy of simulated liquid water content because of a lack of measurements.

PISTE modeled the development of a subsurface temperature gradient, due to solar radiation heating the snowpack just below the surface, while IR radiation cooled the snow surface. A subsurface melt region was simulated, with depth and timing corresponding to the depth and timing of regions of snowpack temperature at $0^{\circ} \mathrm{C}$. This radiation effect has been observed and modeled by others (Brandt and Warren 1993; Morstad et al. 2007; Warren and Wiscombe 1980) in natural, ungroomed snowpacks.

In summary, the new PISTE model shows promise in estimating snow-surface conditions (Figs. 8-11) for this clear-sky case study at RC Whistler, using prescribed in situ measurements as boundary conditions. 
TABLE A1. Glossary of variables used. Note that some of these variables are used in the online supplementary material.

\begin{tabular}{|c|c|c|}
\hline Variable & Description & Unit \\
\hline$a$ & Snow-surface albedo & Dimensionless \\
\hline$C_{E}$ & Bulk transfer coefficient for water vapor & Dimensionless \\
\hline$C_{H}$ & Bulk transfer coefficient for heat & Dimensionless \\
\hline$C_{a}$ & $\approx 1007.6 \mathrm{~J} \mathrm{~kg}^{-1} \mathrm{~K}^{-1}$, the specific heat of air at constant pressure & $\mathrm{J} \mathrm{kg}^{-1} \mathrm{~K}^{-1}$ \\
\hline$C_{i}$ & $=2106 \mathrm{~J} \mathrm{~kg}^{-1} \mathrm{~K}^{-1}$, the specific heat of ice at $0^{\circ} \mathrm{C}$ & $\mathrm{J} \mathrm{kg}^{-1} \mathrm{~K}^{-1}$ \\
\hline$C_{l}$ & $=4217.6 \mathrm{~J} \mathrm{~kg}^{-1} \mathrm{~K}^{-1}$, the specific heat of liquid water at $0^{\circ} \mathrm{C}$ & $\mathrm{J} \mathrm{kg}^{-1} \mathrm{~K}^{-1}$ \\
\hline$C_{p, d}$ & $=1004 \mathrm{~J} \mathrm{~kg}^{-1} \mathrm{~K}^{-1}$, the specific heat at constant pressure for dry air & $\mathrm{J} \mathrm{kg}^{-1} \mathrm{~K}^{-1}$ \\
\hline$C_{p, v}$ & $=1850 \mathrm{~J} \mathrm{~kg}^{-1} \mathrm{~K}^{-1}$, the specific heat at constant pressure for water vapor & $\mathrm{J} \mathrm{kg}^{-1} \mathrm{~K}^{-1}$ \\
\hline$C_{s}$ & Specific heat of snow & $\mathrm{J} \mathrm{kg}^{-1} \mathrm{~K}^{-1}$ \\
\hline$D$ & $=2.2 \times 10^{-5} \mathrm{~m}^{2} \mathrm{~s}^{-1}$, the water vapor diffusion coefficient in air & $\mathrm{m}^{2} \mathrm{~s}^{-1}$ \\
\hline$D_{e}$ & Effective water vapor diffusivity for snow & $\mathrm{m}^{2} \mathrm{~s}^{-1}$ \\
\hline$e_{s, i}$ & Saturation vapor pressure over ice & $\mathrm{kPa}$ \\
\hline$F$ & Heat flow or flux & $\mathrm{W} \mathrm{m}^{-2}$ \\
\hline$F_{E, i}$ & Latent heat flux due to sublimation/deposition at the snow-air interface & $\mathrm{W} \mathrm{m}^{-2}$ \\
\hline$F_{E, l}, l$ & Latent heat flux due to evaporation/condensation at the snow-air interface & $\mathrm{W} \mathrm{m}^{-2}$ \\
\hline$F_{H}$ & Sensible heat flux at the snow-air interface & $\mathrm{W} \mathrm{m}^{-2}$ \\
\hline$F_{\mathrm{IR}, \text { in }}$ & Downwelling longwave radiation at the snow-air interface & $\mathrm{W} \mathrm{m}^{-2}$ \\
\hline$F_{\text {IR,out }}$ & Upwelling longwave radiation at the snow-air interface & $\mathrm{W} \mathrm{m}^{-2}$ \\
\hline$F_{i, \text { vapor }}$ & $\begin{array}{l}\text { Latent heat flux due to water vapor deposition or sublimation at the } \\
\text { snow-air interface }\end{array}$ & $\mathrm{W} \mathrm{m}^{-2}$ \\
\hline$F_{l}$ & Sensible heat flux due to liquid water percolation & $\mathrm{W} \mathrm{m}^{-2}$ \\
\hline$F_{l, \text { vapor }}$ & $\begin{array}{l}\text { Latent heat flux due to water vapor condensation or evaporation at the } \\
\text { snow-air interface }\end{array}$ & $\mathrm{W} \mathrm{m}^{-2}$ \\
\hline$F_{\text {sfc }}$ & Heat flux that only applies at the snow-air interface & $\mathrm{W} \mathrm{m}^{-2}$ \\
\hline$f_{a}$ & Air fraction by volume & - \\
\hline$f_{i}$ & Ice fraction by volume & - \\
\hline$f_{l}$ & Liquid water fraction by volume & - \\
\hline$f_{l, \max }$ & Max allowable liquid water fraction by volume & - \\
\hline$g^{\prime}$ & Unit-converted gravitational acceleration & $\mathrm{kPa}\left(\mathrm{kg} \mathrm{m}^{-2}\right)^{-1}$ \\
\hline$K \downarrow$ & Downwelling shortwave radiation at the snow-air interface & $\mathrm{W} \mathrm{m}^{-2}$ \\
\hline$K \uparrow$ & Upwelling shortwave radiation at the snow-air interface & $\mathrm{W} \mathrm{m}^{-2}$ \\
\hline$k_{\text {eff }}$ & Effective thermal conductivity of snow & $\mathrm{W} \mathrm{m}{ }^{-1} \mathrm{~K}^{-1}$ \\
\hline$L_{d}$ & $\approx 2.83 \times 10^{6} \mathrm{~J} \mathrm{~kg}^{-1}$, the latent heat of deposition & $\mathrm{J} \mathrm{kg}^{-1}$ \\
\hline$L_{f}$ & $\approx 3.34 \times 10^{5} \mathrm{~J} \mathrm{~kg}^{-1}$, the latent heat of fusion & $\mathrm{J} \mathrm{kg}^{-1}$ \\
\hline$L_{v}$ & $\approx 2.5 \times 10^{6} \mathrm{~J} \mathrm{~kg}^{-1}$, the latent heat of vaporization & $\mathrm{J} \mathrm{kg}^{-1}$ \\
\hline$M_{\text {in }}$ & Liquid water mass flux into a snow layer & $\mathrm{kg} \mathrm{m}^{-2} \mathrm{~s}^{-1}$ \\
\hline$M_{\text {out }}$ & Liquid water mass flux out of a snow layer & $\mathrm{kg} \mathrm{m}^{-2} \mathrm{~s}^{-1}$ \\
\hline$\dot{m}_{f}$ & Freezing flux & $\mathrm{kg} \mathrm{m}^{-2} \mathrm{~s}^{-1}$ \\
\hline$P$ & Air pressure & $\mathrm{kPa}$ \\
\hline$q$ & Specific humidity & $\mathrm{kg} \mathrm{kg}^{-1}$ \\
\hline RR & Rain rate & $\mathrm{mm} \mathrm{h}^{-1}$ \\
\hline$R_{v}$ & $=0.461 \mathrm{kPa} \mathrm{K}^{-1} \mathrm{~m}^{3} \mathrm{~kg}^{-1}$, the specific gas constant for water vapor & $\mathrm{kPa} \mathrm{K}^{-1} \mathrm{~m}^{3} \mathrm{~kg}^{-1}$ \\
\hline$\left|S_{\text {in }}\right|$ & Magnitude of solar radiation into the top of a snow layer & $\mathrm{W} \mathrm{m}^{-2}$ \\
\hline$\left|S_{\text {out }}\right|$ & Magnitude of solar radiation leaving the bottom of a snow layer & $\mathrm{W} \mathrm{m}^{-2}$ \\
\hline$T$ & Temperature & $\mathrm{K}$ \\
\hline$T_{\text {air }}$ & Air temperature & $\mathrm{K}$ \\
\hline$t$ & Time & $\mathrm{s}$ \\
\hline$T_{\text {in }}$ & Temperature of liquid water flowing into a snow layer & $\mathrm{K}$ \\
\hline$T_{\text {layer }}$ & Model snow layer temperature & ${ }^{\circ} \mathrm{C}$ \\
\hline$T_{\text {out }}$ & Temperature of liquid water flowing out of a snow layer & $\mathrm{K}$ \\
\hline$T_{\text {rain }}$ & Rain temperature & $\mathrm{K}$ \\
\hline$T_{\text {sfc }}$ & Snow-surface temperature & $\mathrm{K}$ \\
\hline$U$ & 10 -m height wind speed & $\mathrm{ms}^{-1}$ \\
\hline$V_{i}$ & Water vapor mass flux for interior snow layers & $\mathrm{kg} \mathrm{m}^{-2} \mathrm{~s}^{-1}$ \\
\hline$V_{i, \mathrm{sfc}}$ & $\begin{array}{l}\text { Water vapor mass flux at the snow-air interface considering saturation } \\
\text { with respect to ice }\end{array}$ & $\mathrm{kg} \mathrm{m}^{-2} \mathrm{~s}^{-1}$ \\
\hline
\end{tabular}


TABLE A1. (Continued)

\begin{tabular}{|c|c|c|}
\hline Variable & Description & Unit \\
\hline$V_{l, \mathrm{sfc}}$ & $\begin{array}{l}\text { Water vapor mass flux at the snow-air interface considering saturation } \\
\text { with respect to liquid water }\end{array}$ & $\mathrm{kg} \mathrm{m}^{-2} \mathrm{~s}^{-1}$ \\
\hline$\Delta$ & Top minus bottom of snow layer & - \\
\hline$\Delta t$ & Model time step & $\mathrm{s}$ \\
\hline$\Delta z$ & Model snowpack layer thickness & $\mathrm{m}$ \\
\hline$\varepsilon_{\text {eff }}$ & Effective background emissivity & Dimensionless \\
\hline$\varepsilon_{s}$ & Snow emissivity & Dimensionless \\
\hline$\lambda$ & Solar absorption length in snow & $\mathrm{m}$ \\
\hline$\phi$ & Snow porosity & Dimensionless \\
\hline$\rho_{a}$ & Density of air & $\mathrm{kg} \mathrm{m}^{-3}$ \\
\hline$\rho_{l}$ & $=999.84 \mathrm{~kg} \mathrm{~m}^{-3}$, the density of liquid water at $0^{\circ} \mathrm{C}$ & $\mathrm{kg} \mathrm{m}^{-3}$ \\
\hline$\rho_{i}$ & $=916.68 \mathrm{~kg} \mathrm{~m}^{-3}$, the density of solid ice at $0^{\circ} \mathrm{C}$ & $\mathrm{kg} \mathrm{m}^{-3}$ \\
\hline$\rho_{s}$ & Snow density & $\mathrm{kg} \mathrm{m}^{-3}$ \\
\hline$\rho_{\mathrm{vs}, i}$ & Absolute humidity at saturation over ice & $\mathrm{kg} \mathrm{m}^{-3}$ \\
\hline$\sigma$ & $=5.67 \times 10^{-8} \mathrm{~J} \mathrm{~m}^{-2} \mathrm{~s}^{-1} \mathrm{~K}^{-4}$, the Stefan-Boltzmann constant & $\mathrm{J} \mathrm{m}^{-2} \mathrm{~s}^{-1} \mathrm{~K}^{-4}$ \\
\hline$\sigma_{F}$ & Strength or normal failure stress & $\mathrm{kPa}$ \\
\hline$\sigma_{w}$ & Downward imposed normal stress & $\mathrm{kPa}$ \\
\hline
\end{tabular}

\section{b. Model limitations and further work}

The PISTE model introduced here is an exploratory investigation into snow-surface condition forecasts for groomed ski pistes. Still in its early development phase, it lacks the sophistication of other traditional snowpack models, for example, SNOWPACK (Bartelt and Lehning 2002), SNTHERM (Jordan 1991), and CROCUS (Brun et al. 1989). We have shown that an accurate snowsurface temperature simulation is possible for clear skies, without measurements of the snowpack interior, by spinning up PISTE to get realistic initial conditions. However, including more complex boundary forcings such as clouds and precipitation may necessitate input of subsurface measurements.

Avalanche models generally include snow microstructure parameters such as grain size, shape, dendricity, and sphericity, since users care about the strength and structure of the snowpack interior. Since PISTE was designed to simulate snow-surface conditions, on pistes that are groomed to create a somewhat uniform high-density microstructure, it is less crucial to explicitly model snow grains within the snowpack. Nonetheless, future applications with complex atmospheric boundary conditions may require more detailed modeling of the snowpack interior.

Modeling the albedo is an important area for improvement that is linked to snow microstructure, especially since average snow grain size is reduced by grooming. The work of Baker et al. (1990), Bakermans and Jamieson (2008), Livneh et al. (2010), Nolin and Dozier (2000), Pedersen and Winther (2005), Warren (1982), and Warren and Wiscombe (1980), presents potential parameterizations and useful related research. Furthermore, advances in modeling the albedo can be made by incorporating soot, dust, and other chemical and foreign particles, particularly because of the frequency of skiers with waxed skis and grooming equipment having exhaust on ski pistes. Here, studies by Kokhanovsky (2013), Painter et al. (2010), and Warren and Wiscombe (1980) will be useful.

Precipitation is not included in this case study. PISTE has the capacity to incorporate fresh snowfall by adding new snow layers at the top of the snow column, to incorporate rainfall prescribed as an upper-boundary condition, and to model the sensible heat transfer due to liquid water percolation across snow layers, although none of these features have yet been tested. In addition, frost might be better modeled in future versions of PISTE as a new top layer with a lower density.

The effects of grooming are expected to be greatest following fresh snowfall (Fauve et al. 2002), because fresh snow has a much lower density than the packed snow already in the snow column. For this case study there was no snowfall, so we did not see a huge effect from the daily grooming. Further work including adding layers of fresh snowfall will better test the grooming parameterization in PISTE.

It is common for ski piste operators to make snow, for example, if snowfall is scarce and the snowpack is too shallow to race on. This would provide further challenges for input to PISTE. Manmade snowfall amounts (snowpack depth changes) could be measured by a disdrometer and/or using a sonic ranger (like the one in our case study), along with snow-making and grooming schedules.

Snowpack liquid water content was not evaluated in this paper because of a lack of measurements as imposed by the ski piste operator for safety reasons. In the future, 
measurements could be made using a snow fork or a Denoth meter (Denoth 2006; Techel and Pielmeier 2010). These measurements apply only at the snow surface, which is sufficient for ski racing, but further nondestructive methods would need to be developed to measure the entire snowpack depth.

Bethke et al. (2005) aimed to optimize the timing of mechanical water injection, a technique sometimes used in race course preparation to harden the snowpack (Fauve et al. 2002). In reality, this occurs far less frequently than mechanical forcing from skiers and grooming equipment. However, in the future, an option could be added into PISTE to simulate water injection, which changes the mass of the snowpack, as well as properties such as thermal conductivity and latent heating (Olefs and Fischer 2008).

Snow has been observed to decrease in strength as snowpack liquid water content increases (Kattelmann 1987; Mitterer et al. 2011). Specifically, strength is considerably reduced above a liquid water content of around 7\%-8\% by volume (Colbeck 1982; Mitterer et al. 2011; Wakahama 1975). The equation in PISTE relating strength to density applies to dry snow, so it does not account for this. Mitterer et al. (2011) argues that at low liquid water content ( $<3 \%$ by volume), snow strength is similar to or even larger than dry snow strength at $0^{\circ} \mathrm{C}$. Given the liquid water content values modeled for this case study by PISTE $\left(f_{l} \leq 1.2 \%\right.$ by volume), our results are unaffected by this approximation. However, this is an area for improvement in future versions of the model.

The model developed here has only been tested for one point location, on a ski piste at RC Whistler. To get an estimate of the spatial variability of the snow-surface temperature along the ski piste, in order to be useful in race ski preparation, the one-dimensional PISTE model should be applied at multiple locations. Running a 24-h PISTE forecast at a single location currently takes approximately $50 \mathrm{~min}$ on a dual-core desktop computer. Small computer clusters could easily run PISTE forecasts (e.g., for 30 locations every $100 \mathrm{~m}$ along a $3-\mathrm{km}$ race course), because each location is independent of the others, allowing faster parallel computations.

Before PISTE becomes operational, it should be tested for overcast, partly cloudy, and foggy conditions. The radiative boundary conditions could be improved by carrying out a field calibration on the CNR1 (see Michel et al. 2008). For highly accurate boundary conditions, some advances are needed in parameterizing NWP subgrid-scale processes of clouds, radiation, and precipitation. Recently, SNOWPACK has been coupled with NWP models in order to forecast avalanches (Bellaire et al. 2011; Bellaire and Jamieson 2012; Iwamoto et al. 2008). Similarly, in order to be used in operational forecasting, PISTE should be coupled with a numerical weather prediction model.

Acknowledgments. The funding for this research was provided by the Natural Sciences and Engineering Research Council of Canada, Own the Podium 2010, the Vancouver Olympic Committee, and the Geophysical Disaster Computational Fluid Dynamics Center, University of British Columbia, Canada. We also thank Dr. Todd Allinger for posing the problem of pistesurface forecasting and showing its potential value in competitive skiing. Thanks also go to the anonymous reviewers for their knowledgeable input.

Regarding the use of EC Climate Data Online: the website is official work that is published by the Government of Canada, and the reproduction has not been produced in affiliation with or with the endorsement of the Government of Canada.

\section{APPENDIX}

\section{Glossary}

Table A1 explains the variables used.

\section{REFERENCES}

Baker, D. G., D. L. Ruschy, and D. B. Wall, 1990: The albedo decay of prairie snows. J. Appl. Meteor., 29, 179-187, doi:10.1175/ 1520-0450(1990)029<0179:TADOPS > 2.0.CO;2.

Bakermans, L., and B. Jamieson, 2008: A solar warming model (SWarm) to estimate diurnal changes in near-surface snowpack temperatures for back-country avalanche forecasting. Proceedings of the Whistler 2008 International Snow Science Workshop, C. Campbell, S. Conger, and P. Haegeli, Eds., International Snow Science Workshop, 306-315. [Available online at http://arc.lib.montana.edu/snow-science/item/48.]

Bartelt, P., and M. Lehning, 2002: A physical SNOWPACK model for the Swiss avalanche warning. Part I: Numerical model. Cold Reg. Sci. Technol., 35, 123-145, doi:10.1016/ S0165-232X(02)00074-5.

Bellaire, S., and B. Jamieson, 2012: Nowcast with a forecastSnow cover simulations on slopes. Proceedings of the Anchorage 2012 International Snow Science Workshop, International Snow Science Workshop, 172-178. [Available online at http://arc.lib.montana.edu/snow-science/ item.php?id=1577.]

,-- , and C. Fierz, 2011: Forcing the snow-cover model snowpack with forecasted weather data. Cryosphere, 5, 11151125, doi:10.5194/tc-5-1115-2011; Corrigendum, 7, 511-513, doi:10.5194/tc-7-511-2013.

Bethke, S., M. Fauve, C. Fierz, M. Lehning, O. Martius, H. Rhyner, and W. Ammann, 2005: Predicting snow conditions for the optimization of race piste preparation. Science and Skiing III, Meyer \& Meyer Sport, 395-400.

Brandt, R. E., and S. G. Warren, 1993: Solar-heating rates and temperature profiles in Antarctic snow and ice. J. Glaciol., 39 (131), 99-110. 
Brun, E., E. Martin, V. Simon, C. Gendre, and C. Coleou, 1989: An energy and mass model of snow cover suitable for operational avalanche forecasting. J. Glaciol., 35 (121), 333-342.

Chapman, S., 2008: Fortran 95/2003 for Scientists and Engineers. 3rd ed. McGraw-Hill, 974 pp.

Colbeck, S. C., 1982: An overview of seasonal snow metamorphism. Rev. Geophys., 20, 45-61, doi:10.1029/RG020i001p00045.

Denoth, A., 2006: A comparative study of instruments for measuring the liquid water content of snow. J. Appl. Phys., 56, 2154-2160, doi:10.1063/1.334215.

Environment Canada, 2012: National climate data and information archive. [Available online at www.climate.weatheroffice.gc.ca/ climateData/canada_e.html.]

Essery, R., S. Morin, Y. Lejeune, and C. Ménard, 2013: A comparison of 1701 snow models using observations from an alpine site. Adv. Water Resour., 55, 131-148, doi:10.1016 j.advwatres.2012.07.013.

Fauve, M., H. Rhyner, and M. Schneebeli, 2002: Preparation and Maintenance of Pistes: Handbook for Practitioners. Swiss Federal Institute for Snow and Avalanche Research, 133 pp.

,$- \ldots$, A. Lüthi, M. Schneebeli, and M. Lehning, 2008: Putting snow knowledge into the development of winter sports equipment. Sports Technol., 1, 145-151, doi:10.1002/jst.13.

Howard, R., and R. Stull, 2011: Forecasting sun versus shade in complex terrain for the 2010 winter Olympic and Paralympic games. Bull. Amer. Meteor. Soc., 92, 1303-1309, doi:10.1175/ 2011BAMS-D-11-00017.1.

$\ldots$, and _ 2013a: IR radiation from trees to a ski run: A case study. J. Appl. Meteor. Climatol., 52, 1525-1539, doi:10.1175/ JAMC-D-12-0222.1.

_ tion over a groomed ski run under clear skies. J. Appl. Meteor. Climatol., 52, 1540-1553, doi:10.1175/JAMC-D-12-0245.1.

Iwamoto, K., S. Yamaguchi, S. Nakai, and A. Sata, 2008: Forecasting experiments using the regional meteorological model and the numerical snow cover model in the snow disaster forecasting system. J. Nat. Disaster Sci., 30, 35-43, doi:10.2328/ jnds.30.35.

Jordan, R., 1991: A one-dimensional temperature model for a snow cover: Technical documentation for SNTHERM.89. Tech. Rep. SR-91-16, Cold Regions Research and Engineering Laboratory, $61 \mathrm{pp}$.

Kattelmann, R., 1987: Some measurements of water movement and storage in snow. IAHS Publ., 162, 245-254. [Available online at http://iahs.info/uploads/dms/iahs_162_0245.pdf.]

Kokhanovsky, A., 2013: Spectral reflectance of solar light from dirty snow: A simple theoretical model and its validation. Cryosphere, 7, 1325-1331, doi:10.5194/tc-7-1325-2013.

Livneh, B., Y. Xia, K. E. Mitchell, M. B. Ek, and D. P. Lettenmaier, 2010: Noah LSM snow model diagnostics and enhancements. J. Hydrometeorol., 11, 721-738, doi:10.1175/2009JHM1174.1.

Matson, D. L., and R. H. Brown, 1989: Solid-state greenhouses and their implications for icy satellites. Icarus, 77, 67-81, doi:10.1016/0019-1035(89)90007-9.
McClung, D., and P. Schaerer, 2006: The Avalanche Handbook. 3rd ed. Mountaineers Books, 342 pp.

Mellor, M., 1975: A review of basic snow mechanics. IAHS Publ., 114, 251-291. [Available online at http://iahs.info/uploads/dms/ iahs_114_0251.pdf.]

Meyer, B., 1988: Object-Oriented Software Construction. 1st ed. Prentice Hall, 534 pp.

Michel, D., R. Philipona, C. Ruckstuhl, R. Vogt, and L. Vuilleumier, 2008: Performance and uncertainty of CNR1 net radiometers during a one-year field comparison. J. Atmos. Oceanic Technol., 25, 442-451, doi:10.1175/2007JTECHA973.1.

Mitterer, C., H. Hirashima, and J. Schweizer, 2011: Wet-snow instabilities: Comparison of measured and modelled liquid water content and snow stratigraphy. Ann. Glaciol., 52, 201-208, doi:10.3189/172756411797252077.

Morstad, B. W., E. E. Adams, and L. R. McKittrick, 2007: Experimental and analytical study of radiation-recrystallized near-surface facets in snow. Cold Reg. Sci. Technol., 47, 90101, doi:10.1016/j.coldregions.2006.08.023.

Nolin, A. W., and J. Dozier, 2000: A hyperspectral method for remotely sensing the grain size of snow. Remote Sens. Environ., 74, 207-216, doi:10.1016/S0034-4257(00)00111-5.

Olefs, M., and A. Fischer, 2008: Comparative study of technical measures to reduce snow and ice ablation in alpine glacier ski resorts. Cold Reg. Sci. Technol., 52, 371-384, doi:10.1016/ j.coldregions.2007.04.021.

- and M. Lehning, 2010: Textile protection of snow and ice: Measured and simulated effects on the energy and mass balance. Cold Reg. Sci. Technol., 62, 126-141, doi:10.1016/ j.coldregions.2010.03.011.

Painter, T. H., J. S. Deems, J. Belnap, A. F. Hamlet, C. C. Landry, and B. Udall, 2010: Response of Colorado River runoff to dust radiative forcing in snow. Proc. Natl. Acad. Sci. USA, 107, 17125-17130, doi:10.1073/pnas.0913139107.

Pedersen, C. A., and J.-G. Winther, 2005: Intercomparison and validation of snow albedo parameterization schemes in climate models. Climate Dyn., 25, 351-362, doi:10.1007/s00382-005-0037-0.

Philipona, R., C. Fröhlich, and C. Betz, 1995: Characterization of pyrgeometers and the accuracy of atmospheric long-wave radiation measurements. Appl. Opt., 34, 1598-1605, doi:10.1364/ AO.34.001598.

Techel, F., and C. Pielmeier, 2010: Point observations of liquid water content in natural snow-Investigating methodical, spatial and temporal aspects. Cryosphere, 4, 405-418, doi:10.5194/ tc-5-405-2011.

Wakahama, G., 1975: The role of meltwater in densification processes of snow and firn. IAHS Publ., 114, 66-72. [Available online at http://iahs.info/uploads/dms/iahs_114_0066.pdf.]

Warren, S. G., 1982: Optical properties of snow. Rev. Geophys., 20, 67-89, doi:10.1029/RG020i001p00067.

, and W. J. Wiscombe, 1980: A model for the spectral albedo of snow. II: Snow containing atmospheric aerosols. J. Atmos. Sci., 37, 2734-2745, doi:10.1175/1520-0469(1980)037<2734: AMFTSA $>2.0 . \mathrm{CO} ; 2$. 